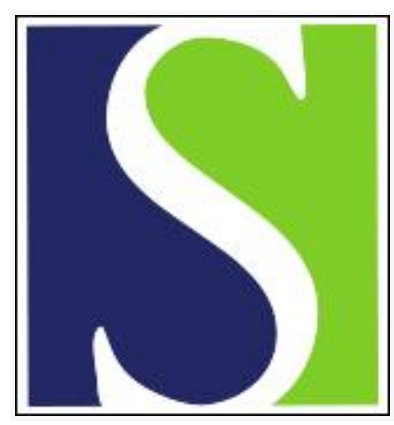

Scand J Work Environ Health 1980;6(1):66-72

https://doi.org/10.5271/sjweh.2632

Issue date: Mar 1980

Diet, physiological work and accident incidence of forge workers.

by Brooke JD, Toogood S, Green LF

Key terms: 5-hydroxytryptamine; accident; accident incidence; diet; energy expenditure; forge worker; glucose supplement; physiological work; worker

This article in PubMed: www.ncbi.nlm.nih.gov/pubmed/7384769

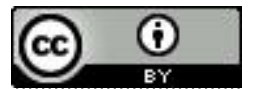




\title{
Diet, physiological work and accident incidence of forge workers
}

\author{
by John D Brooke, PhD, ${ }^{1}$ Susan Toogood, BSc, ${ }^{2}$ Leslie F Green, $\mathrm{BSc}^{3}$
}

\begin{abstract}
BROOKE JD, TOOGOOD S, GREEN LF. Diet, physiological work and accident incidence of forge workers. Scand $j$ work environ health 6 (1980) 66-72. Three experiments were made to study the following three factors in forge workers in a hot shop: (a) the metabolic load of daily work, (b) dietary intake, and (c) the effect of supplementing morning dietary intake with glucose syrup ingestion upon accident incidence. High energy output, mean $9.7 \mathrm{MJ}(2,300 \mathrm{kcal})$, complemented high energy intake, mean $15 \mathrm{MJ}(3,600 \mathrm{kcal})$, a shortage of intake in the morning being compensated for after work in the evening. Alcohol intake represented 1 to $2 \mathrm{MJ}$ (240 to $480 \mathrm{kcal}$ ) of the evening intake. Glucose syrup ingestion to reverse increased use of fats in the metabolic fuel in the early morning, in a double-blind design, resulted in a significant reduction of accidents. The effect may lie in altered levels of 5-hydroxytryptamine in the central nervous system. Caution in interpreting the effect upon accidents is necessary since the number of subjects was small (57) and the time span limited (18 weeks).
\end{abstract}

Key terms: accidents, diet, energy expenditure, forge workers, glucose supplement, 5-hydroxytryptamine.

In industrial production, the metabolic load on workers is important. Disequilibrium in the provision of oxygen or in the availability of nutrients may lead to fatigue, absenteeism, and performance errors.

Numerous studies have been made of physical work and physiological load. The effect of dietary change upon the mixture of metabolic fuels used by active skeletal muscle has also been studied $(1,4,5,8)$. In addition research has been made into the effect of meal omission on human performance $(14,21)$. More recently, Richards (20) indicated that disruption of the normal pattern of feeding can be deleterious to

1 School of Human Biology, University of Guelph, Canada.

2 Human Performance Laboratory, University of Salford, England.

3 Applied Research and Development Unit, Beecham Products, Leatherhead, England.

Reprint requests to: Dr JD Brooke, Director, School of Human Biology, University of Guelph, Ontario N1G 2W1, Canada. performance, and Christian (9) implicated improper short-term nutrition in the incidence of road accidents. There have, however, been few attempts to provide such information in connection with the biology of occupational work. The present study is a step towards such a profile. It was concerned with assessing daily energy intake and expenditure, body weight distribution, accident incidence, and an hypothesized positive effect of digestible carbohydrate (CHO), as a dietary supplement, upon accident incidence in one group of forge workers in England.

\section{Methods}

\section{Subjects}

Seventy male subjects working in the hot shop of a forge in central Lancashire, England, formed the experimental sample. Their ages ranged from 20 to 55 a. 


\section{Experimental series}

Three experiments were carried out. First, a pilot study was made of three subjects to indicate the level of energy expenditure involved in working in the hot shop of the forge. As discussion with the workers revealed that in the premorning work period little food was ingested, the first nutrition of the day for many workers being taken at the midmorning break, additional studies were undertaken.

The second experiment involved the observation of 12 subjects over $3 \mathrm{~d}$. In addition to having their oxygen uptake and respiratory quotient (RQ) measured, the subjects were provided early in the morning with two dietary supplements on separate days, either $250 \mathrm{ml}$ of a glucose syrup drink, energy value 1.486 MJ (350 kcal), or $250 \mathrm{ml}$ of a low-energy drink similarly colored and flavored but with an energy value of less than $20 \mathrm{~kJ}(5 \mathrm{kcal})$. Since the second pilot study revealed that, in the early morning, accident incidence was high and respiratory quotients low and that $\mathrm{CHO}$ supplementation raised the respiratory quotients, a third experiment was conducted.

This third experiment extended over 18 weeks and involved 57 subjects. Measures of $\mathrm{RQ}$ and blood glucose were made from a random sampling of subjects over the workday. In addition the two dietary supplements described previously were to be taken daily between 0800 and 1000 . The subjects acted as their own controls; initially, by random sampling, half the subjects took $500 \mathrm{ml}$ each of one supplement and half the other supplement similarly. This presentation of dietary treatments to the subjects was reversed after five weeks, reversed again after another five weeks, and finally again after an additional four weeks to provide a balanced presentation. Daily diets and body weights were recorded.

\section{Experimental techniques}

The energy expenditure of the subjects was assessed by measurement of oxygen uptake, $R Q$, and cardiac rate. The first two parameters were obtained with Kofranyi-Michaelis respirometers and sub- sequent $\mathrm{O}_{2}$ and $\mathrm{CO}_{2}$ gas analysis by a Haldane apparatus as described by Brooke \& Davies (3). Cardiac rate was calculated from 10 consecutive R-R intervals of the electrocardiograph, obtained by radio telemetry. The reliability coefficient from repeated measurements was 0.89 for cardiac rate and 0.91 for oxygen uptake.

The composition of the metabolic mixture used as fuel for the active skeletal muscles was estimated from the RQ (with the assumption of no significant involvement of altered protein metabolism) by use of Carpenter's tables (7). Blood glucose was measured by the glucose oxidase micro technique and capillary blood sampling as described by Green (13). The measurement error $(95 \%)$ of the blood glucose determination was $\pm 150 \mu \mathrm{mol} \mathrm{l}^{-1}$ ( $\pm 2.7 \mathrm{mg} 100 \mathrm{ml}^{-1}$ ), and the RQ determinations provided reliability coefficients between 0.9 and 0.7 .

In the third experiment the daily diet was recorded in detail with the use of standardized dietary record sheets and verbal interview techniques for the same 10 workers on one day in each of four consecutive months and also for 44 workers once in the final month. From the food tables of McCance \& Widdowson (16) the proportion of daily energy derived from fat, CHO, protein, and alcohol was determined. This information was also used to obtain the within-day distribution of energy intake over the five periods of the day shown in fig 1 . In this third experiment the body weights of the subjects were recorded at the beginning and end of the 18 weeks.

In the study of accident incidence, after the second pilot study, accidents recorded in the Factory Accident Book over the

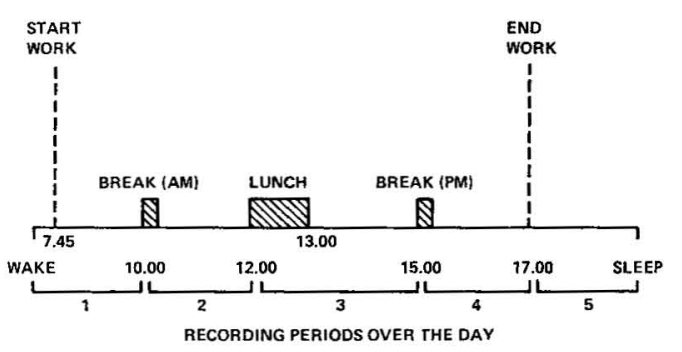

Fig 1. Dietary recording periods of the forge workers' day. 
previous 16 months were reviewed, and their incidence was tabulated for each of the four workday segments shown in fig 1. During the third experiment a similar tabulation was made of accidents occurring to men on the two dietary supplements. In this latter experiment 17 subjects did not cooperate in taking the dietary addition, and their accident data were recorded as a separate, noncooperating group. (The accidents recorded ranged in severity from abrasions of the fingers to fracture of the humerus.)

An inferential statistical analysis at the 0.05 level was made for the parametric physiological data, with reference to the effects of the two dietary supplements, with the unpaired t-test or for the involvement of the time periods with an analysis of variance. For the accident data, a chisquare analysis was used; any accidents occurring to the same subject under both treatments was removed as recommended by McNemar (18).

\section{Results}

\section{Daily diet}

The mean daily energy intake of the 44 workers measured once in August was $14.71 \mathrm{MJ}(3,514 \mathrm{kcal})$ [SD 4.95 MJ $(1,182$ kcal)].

Fig 2 illustrates the distribution of this intake over the workday and also the

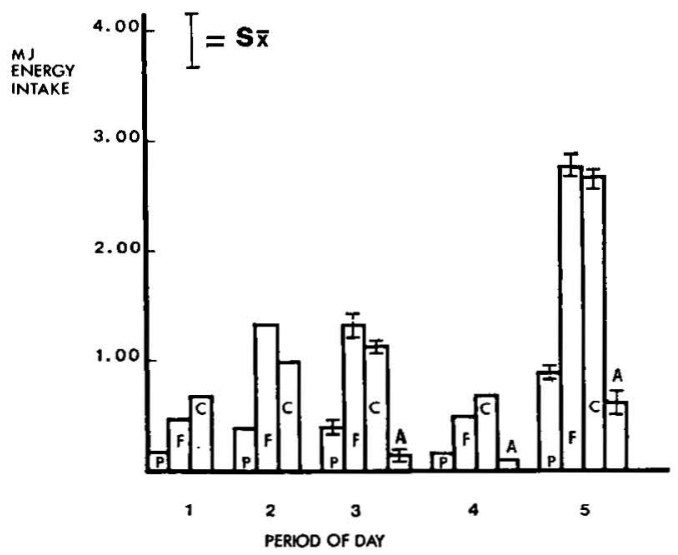

Fig 2. Mean distribution of daily energy intake as protein $(P)$, fat $(F)$, carbohydrate $(C)$, and alcohol (A) for 40 forge workers analyzed on one day in August. amounts due to $\mathrm{CHO}$, fat, protein, and alcohol for each of these daily periods. For the 10 workers whose intake was recorded one day a month for four months, the daily energy intake is shown in fig 3; it ranged from 17 to 19 MJ $(4,000-4,500$ kcal). An apparent trend of decreasing intake over the successive months so that $17 \mathrm{MJ}(4,000 \mathrm{kcal})$ constituted the August value was not statistically significant.

\section{Energy expenditure}

The daily mean energy expenditure at work, calculated from data on oxygen uptake and $R Q$ from the 15 subjects involved in the first two experiments, was $9.66 \mathrm{MJ}$ $(2,307 \mathrm{kcal})$ [SD $283 \mathrm{~kJ}(70 \mathrm{kcal})]$. The mean cardiac rate per minute was 103 (SD 14.8).

\section{Metabolic fuel}

The largest difference between RQs in the two treatments occurred between 1000 and 1200 (mean 0.84 and SD 0.10 for the lowenergy supplement and 0.92 and 0.14 , respectively, for the glucose syrup supplement, $N=19$ ). A similar trend occurred over the morning and whole day. Also, in the preliminary experiments involving 12 subjects, similar differences were observed for this period with a mean RQ of 0.79 for unsupplemented subjects and 0.83 for workers provided with glucose syrup sup-

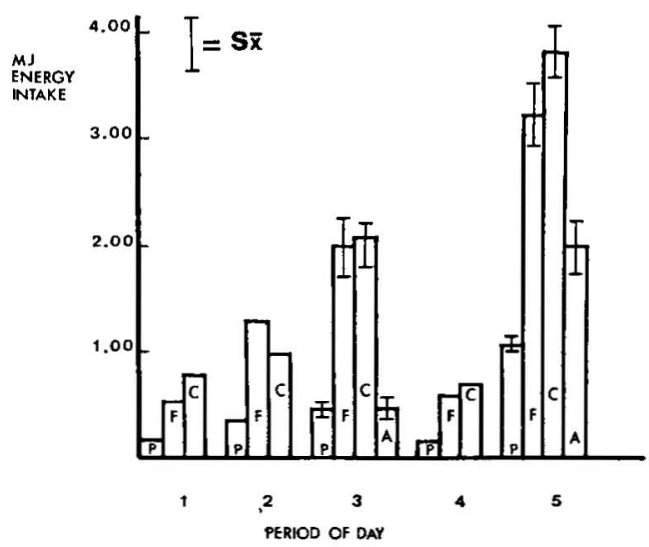

Fig 3. Mean distribution (May through August) of daily energy intake as protein $(P)$, fat $(F)$, carbohydrate (C), and alcohol (A) for 10 forge workers interviewed one day a month. 
plements. However, no difference between diets was statistically significant; large standard deviations were noted.

The mean blood glucose levels of the two groups receiving dietary supplements and the noncooperative group of the third experiment are shown in fig 4. During the first three-quarters of the day, the subjects supplemented with glucose syrup in the morning showed a higher blood glucose level. Standard deviations for this data around each of the mean treatment-time points were again large, ranging from 0.7 to $1.0 \mathrm{mmol}^{-1}$ (12.6 to $18.0 \mathrm{mg} 100 \mathrm{ml}^{-1}$ ). Between treatment differences, at each of the time points by analyses of variance, were not significant.

\section{Body weight}

Fig 5 describes the distribution of body weights at the start of the third experiment in the sample of 57 men, mean value $71.64 \mathrm{~kg}(158 \mathrm{lb})$ [SD $10.49 \mathrm{~kg}(23 \mathrm{lb})]$. Over this experiment, the mean body weight rose $360 \mathrm{~g}(0.8 \mathrm{lb})$ [SD $2.28 \mathrm{~kg}(3 \mathrm{lb})$ ], a nonsignificant change.

\section{Accidents}

The accident incidence appearing in the 16-month retrospective survey is shown in table 1. More accidents occurred in the morning than in the afternoon period, and more occurred in the premorning than the postmorning break sessions.

In conjunction with the summary of this data, table 2 shows the accident incidence during the subsequent four-month experiment with dietary treatment. It can be seen that more accidents occurred under the low-energy treatment than under the glucose syrup treatment, and most accidents occurred in the noncooperating group. With the exception of the low-

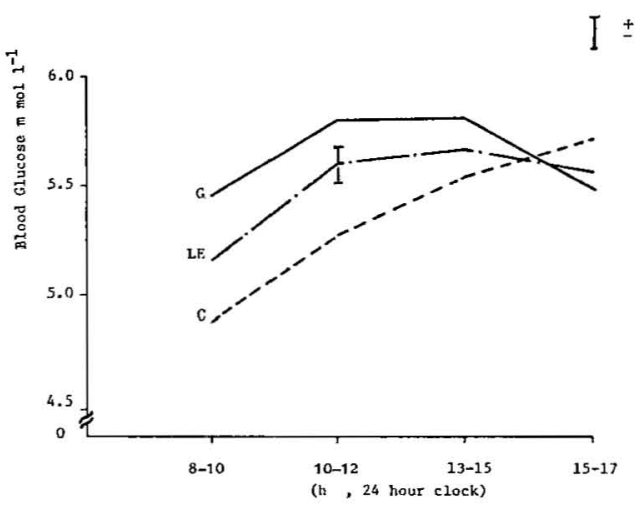

Fig 4. Mean blood glucose over the workday of the men given an early morning supplement of glucose syrup soln $(G)$, the men given a corresponding low-energy drink (LE), and the noncooperating men (C).

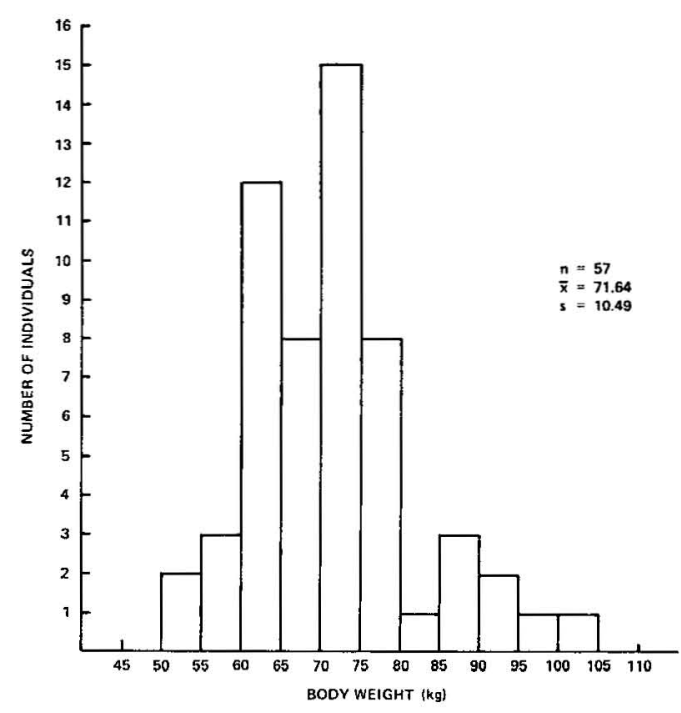

Fig 5. Body weight distribution at the start of the main experiment.

Table 1. The number of accidents in the forge as determined from the 16-month retrospective survey.

\begin{tabular}{cccccc} 
Morning work & & & Afternoon work & $\begin{array}{c}\text { Overall } \\
\text { total }\end{array}$ \\
\hline $0800-09591000-1200$ & Total & $1300-14591500-1700$ & Total
\end{tabular}

Number of

accidents

62

54

116

42

44

86

202 
Table 2. Mean accident incidence per 100 workers per week in the 18-week experimental study ( 57 men under dietary treatment and 19 noncooperative men and in the 16-month retrospective survey 80 men).

\begin{tabular}{lcccc}
\hline & \multicolumn{3}{c}{ 18-week study } & 16-month survey \\
\cline { 2 - 4 } & $\begin{array}{c}\text { Glucose } \\
\text { syrup } \\
\text { group }\end{array}$ & $\begin{array}{c}\text { Low- } \\
\text { energy } \\
\text { group }\end{array}$ & $\begin{array}{c}\text { Non- } \\
\text { cooperative } \\
\text { group }\end{array}$ & 16 \\
\cline { 2 - 4 } $\begin{array}{l}\text { Accident } \\
\text { incidence }\end{array}$ & 0.78 & 1.95 & 9.8 & 2.15 \\
\hline
\end{tabular}

energy versus retrospective survey comparison, all differences between the groups were statistically significant. Fig 6 shows the distribution of the accidents in the third experiment over the workday and by treatments.

\section{Discussion}

The mean energy intake of approximately $15 \mathrm{MJ}(3,500 \mathrm{kcal})$ per day for these forge workers is comparable to that suggested by Davidson et al (10) of $13-17$ MJ $((3,100-$ $4,100 \mathrm{kcal})$ per day for males in very active occupations. Two methods of measuring this intake were used in the present study: (a) interviews once of 44 workers and (b) interviews taken four times at monthly intervals from 10 workers. The fact that no significant difference was found between the mean values for the measures repeated over the months suggests that the

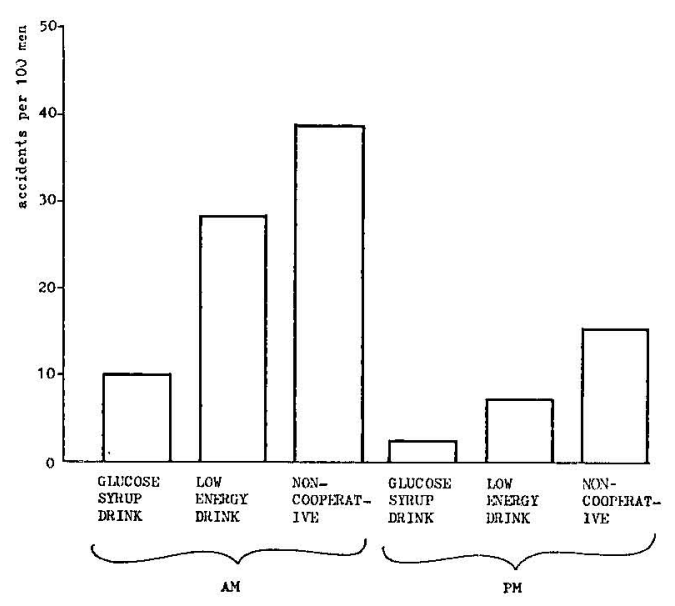

Fig 6. Distribution of accidents in the morning and afternoon treatments (main study). approaches may be interchangeable. It was noted that the mean daily alcohol intake with a total energy value between 1.0 and $2.0 \mathrm{MJ}$ (240-480 kcal) made a meaningful contribution to the total energy intake.

The energy expenditure from the daily work loads averaged approximately 9.66 MJ $(2,300 \mathrm{kcal})$, a level of demand falling at the top of Scholz's category of hard manual work (12). It is not to be expected that harder physical work could be habitually tolerated by these workers. It is clear that the high dietary energy intake was substantially in response to the energy expenditure demands of the occupation. In the present results, the balance between energy intake and expenditure was close, as seen by the stability of the body weight of the group as a whole. Over the four-month period, no significant change occurred. There was considerable individual variation witnessed at the extremes of the distribution, one subject losing $6.0 \mathrm{~kg}$ $(13 \mathrm{lb})$ and one gaining $5.0 \mathrm{~kg}(11 \mathrm{lb})$ over the four months.

Over the day, the intake of energy followed a linear function with time, as shown in fig 2 and 3 . As high energy expenditure was confined to the first $9 \mathrm{~h}$ of the waking day, there was an imbalance between energy intake and expenditure within the day. The short fall in intake during the workday was met during the lower energy expenditure of the evening period when intake exceeded expenditure. In the culture of such workers, the evening meal is usually large. Such imbalance within the day would have little effect upon the stability of intake and expenditure over weeks or months, and hence little change was seen in the average body weight over the period of the third experiment. 
However, within-day fluctuations in energy intake versus expenditure may affect behavior if there are short-term fluctuations in nutrients essential to the efficiency of performance. Such relationships have been observed for variation in the availability of metabolic CHO. In the 1930s, Haggard \& Greenberg (14), from studies of meal spacing, suggested an effect of nutrition upon performance, but methodological weaknesses make interpretation difficult. More recently, Simpson et al (22) reported that skill deterioration (pursuit rotor tracking) due to $3-\mathrm{h}$ fasting and noise stress is alleviated by the ingestion of glucose, and Brooke (2) showed that an extension occurs in reaction time components under depletion of body CHO stores, with some amelioration or removal of this effect by the ingestion of glucose syrup drink. It appears that such within-day fluctuations in CHO intake as those reported in the present study may relate to a change in performance, a hypothesis advanced with some supporting data by Christian (9) to account for some road accidents. Such an effect might be expected, particularly in an environment such as the forge, where loads from heat, sound, illumination, dust, noxious fumes, and physical work all converge upon the worker [cf McCallum (15)].

It is therefore noteworthy that, in the present study, errors in performance were altered by dietary $\mathrm{CHO}$ intake. These workers were often overnight fasted at the start of the workday. Their alcohol intake the evening before would predispose them to ethanol-induced hypogIycemia (11), and the initiation of activity would be an additional potential hypoglycemic factor (6). In the third experiment, when subjects were receiving a dietary supplement of glucose syrup early in the workday, the incidence of accidents decreased in comparison to that for the period when they received a low-energy dietary supplement or to that of the previous months. With the known marked variation that can occur in accident incidence in some occupational work situations [cf McCormick (17)], great credence should not be placed on the magnitude of the change in accidents in the present study. However, that there was a significant effect in the direction hypothesized and in conjunction with accompanying metabolic state is worthy of attention.

It is also of interest to note that the accident incidence in the group of subjects not wishing to participate in the dietary experiment was high. Of the 17 men, accidents over the four-month period were recorded for 15 . It might be argued that having taken a stand against the experiment, these men were more at risk. However, it appears improbable, for the researcher "on site" in the factory made little intrusion into the general work environment. It is more feasible to consider whether underlying characteristics of this group of men led them both to reject participation in the experiment and also to be more liable to accident. With regard to the observations on the metabolic substrate underlying work performance, it is noted that the RQ values obtained were similar to those reported by Haggard \& Greenberg (14), the measures from the lowenergy treatment occupying the lower part of their range and those from the $\mathrm{CHO}$ treatment, the upper part. The demonstration of this substrate for RQ and blood glucose would have been more sound with an improved experimental design. The present design randomly sampled subjects from each treatment stratum and for each period in the day. It would have been preferable to have made a stratified random sampling of subjects over treatments and then subsequently to have followed a subject through serial sampling over the day for each of the treatments. This procedure would have enabled individual timing of ingestion of the glucose syrup drink to be precisely located. Standard deviations would have been reduced accordingly. The improved design would also have indicated the degree of individual variation in tolerance to CHO load. It is felt that some of the nonsignificance in metabolic parameters over dietary treatments in the third experiment was due to the design used.

The results of the present work indicate the need to pursue the effect of transient malnutrition upon performance and mental states in healthy human beings as one possible effect within the domain of metabolic correlates of fatigue, performance 
deterioration and occupational accidents. Some work has been done on the cause of performance modification with $\mathrm{CHO}$ ingestion, but the picture is not yet clear. It may be that subsequent insulin mobilization affects nervous function either by increasing vagal activity or by altering the level of the central nervous transmitter 5-hydroxytryptamine by increasing the binding of tryptophan to albumin freed from binding to free fatty acids (23). Or it may be that there is insufficient support for the metabolism of nerve cells with their high dependence upon glucose as fuel. Alternatively, it may be that feelings of little energy intake or fasting are perceived by some individuals as discomfort which commands some of the central attentive space (19). The present results suggest that additional study in this domain of nutrition and performance might be worthwhile.

\section{Acknowledgments}

This research was supported by grants from the Science Research Council and from Beecham Products (UK).

The assistance of the workers and management of the forge are gratefully acknowledged.

\section{References}

1. Bergström J, Hultman E. Synthesis of muscle glycogen in man after glucose and fructose infusion. Acta med scand 182 (1967) 93-107.

2. Brooke JD. Effects on fractionated reaction time of sustained movement to deplete metabolic carbohydrate. In: Landry $\mathrm{F}$, Orban WAR, eds. Exercise physiologyfitness and performance capacity studies. Symposia Specialists, Miami, FA 1978, pp $171-181$.

3. Brooke JD, Davies GJ. Comment on energy expenditure of racing cyclists. Ergonomics 16 (1973) 237-238.

4. Brooke JD, Davies GJ, Green LF. Nutrition during severe prolonged exercise in trained cyclists. Proc nutr soc 31 (1973) 93A.
5. Brooke JD, Green LF. The effect of a high carbohydrate diet on human recovery following prolonged work to exhaustion. Ergonomics 17 (1974) 489-497.

6. Brooke JD, Llewelyn K, Green LF. Time of glucose syrup ingestion to alleviate initial exercise hypoglycaemia. Proc nutr soc 35 (1976) 136A.

7. Carpenter TM. Tables, factors and formulas for computing respiratory exchange and biological transformations of energy. 4th ed. Carnegie Institute, Washington, DC $1964, \mathrm{p} 104$.

8. Christensen EH, Hansen O. Arbeitsfähigkeit und Ehrnährung. Skand arch physiol 21 (1939) 160-172.

9. Christian MS. Letter to the editor - Multiple crashes on motorways. $\mathrm{Br}$ med $\mathrm{j} 2$ (1972) 295.

10. Davidson S, Passmore R, Brock JF, Truswell AS. Human nutrition and dietetics. 6th ed. Churchill Livingstone, London 1975, p 30 .

11. Freinkel N, Singer DL, Arky RA, Bleicher SJ, Anderson JB, Silbert CK. Alcohol hypoglycaemia: I. Carbohydrate metabolism of patients with clinical alcohol hypoglycaemia and the experimental reproduction of the syndrome with pure ethanol. $\mathrm{J}$ clin invest 42 (1963) 1112-1133.

12. Grandjean E. Physiologische Arbeitsgestaltung. Ott-Verlage, Munich 1963, p 62.

13. Green LF. Blood glucose measurement in field trials. Br $\mathrm{j}$ sports med 6 (1972) 116.

14. Haggard HW, Greenberg LA. Diet and physical efficiency. Yale University Press, New Haven 1935, p 54.

15. McCallum RI. Respiratory disease in foundrymen. $\mathrm{Br} \mathrm{j}$ ind med 29 (1972) 341344.

16. McCance RA, Widdowson EM. The composition of foods. 3rd ed rev. Her Majesty's Stationery Office, London 1960.

17. McCormick EJ. Human factors in engineering and design. 4th ed. McGraw Hill, Toronto 1976, p 20.

18. MeNemar $Q$. Note on the sampling error of the differences between correlated proportions or percentages. Psychometrika 12 (1947) 153-257.

19. Moray N. Attention. Hutchinson, London 1969.

20. Richards MMC. Studies on breakfast and mental performance. Nutrition 26 (1972) $219-223$.

21. Stare JF et al, eds. Physiologic results of breakfast habits. Nutr rev 15 (1957) 196198.

22. Simpson GC, Cox T, Rothschild DR. The effects of noise stress on blood glucose level and skilled performance. Ergonomics 17 (1974) 481-487.

23. Wurtman RJ, Fernstrom JD. Effects of the diet on brain transmitters. Nutr rev 32 (1974) $193-200$. 